\title{
Phylogenetic analyses of the Fusarium graminearum species complex isolated from soybean in Argentina and Brazil
}

\author{
M. L. Chiotta ${ }^{1,2}$ - M. S. Alaniz Zanon ${ }^{1}$ - G. Giaj-Merlera ${ }^{1,2}$ • D. Tessmann ${ }^{3}$. \\ G. G. Barros ${ }^{1,2}$ - S. Chulze Ch, $^{1,2}$
}

Received: 13 May 2015 / Accepted: 11 October 2015 /Published online: 20 October 2015

(C) Australasian Plant Pathology Society Inc. 2015

\begin{abstract}
Soybean is one of the most economically important crops in Argentina and Brazil. However, there is limited information on the biodiversity of the FGSC from soybean as compared to other crops of large-scale growing such as wheat and maize. A phylogenetic recognition of the Fusarium graminearum species complex (FGSC) isolated from soybean in Argentina and Brazil was performed in order to identify species responsible for trichothecene production. Sequences of genes encoding for the partial translation elongation factor, the 3-O-acetyltransferase and a putative reductase were analysed by the Maximum Parsimony method. Although the present study has focused on a limited number of isolates, this is the first report that provides evidence of the presence of at least four species within the FGSC associated with soybean in Argentina: F. graminearum sensu stricto, F. cortaderiae, $F$. meridionale and $F$. boothii. In addition, $F$. graminearum sensu stricto was detected for the first time among Brazilian isolates from soybean.
\end{abstract}

Keywords Fusarium graminearum species complex · Phylogeny $\cdot$ Soybean $\cdot$ Trichothecenes

\section{G. G. Barros}

gbarros@exa.unrc.edu.ar

1 Departamento de Microbiología e Inmunología, Facultad de Ciencias Exactas Físico-Químicas y Naturales, Universidad Nacional de Río Cuarto, Río Cuarto, Córdoba, Argentina

2 Consejo Nacional de Investigaciones Científicas y Técnicas (CONICET), Buenos Aires, Argentina

3 Universidade Estadual de Maringá, Av. Colombo, 5.790. Jd. Universitário, Maringá, Paraná, Brasil
Members of the Fusarium graminearum species complex (FGSC) are economically important pathogens that cause significant yield and quality losses in the production of cereal crops. Before the year 2000 this complex was considered a single species, Fusarium graminearum. Since then, DNA-based analyses have resolved the FGSC into at least sixteen lineages (O'Donnell, 2004; Starkey et al. 2007; O'Donnell et al. 2008; Yli-Mattila et al. 2009; Sarver et al. 2011). Among them, Fusarium graminearum sensu stricto has long been considered the main fungal pathogen from this complex. Fusarium graminearum causes the Fusarium head blight (FHB) disease in wheat and barley and the ear rot of maize (Goswami and Kistler 2004). Recently, this and other species within the FGSC were identified as pathogens of soybean in South America, producing pod discoloration, seed decay and root rot (Martinelli et al. 2004; Pioli et al. 2004; Barros et al. 2014). However, there is limited information on the biodiversity of the FGSC from soybean, as compared to other crops of large-scale growing such as wheat and maize. Within the FGSC, three strain-specific B-trichothecene chemotypes have been identified: the NIV, the 3-ADON and the 15-ADON. Trichothecene toxin differences appear to be adaptive since three strain-specific profiles have been maintained by balancing selection over multiple speciation events (Ward et al. 2002). Based on this context, the aims of the present study were: i) to evaluate the biodiversity of species within the FGSC isolated from soybean in Argentina and Brazil through phylogenetic studies, using Maximum Parsimony analyses; ii) to correlate the phylogenetic species with the trichothecene chemotypes of the isolates.

In this study, a total of 32 isolates from soybean were included (Table 1). The isolates were morphologically identified within the FGSC according to Leslie and Summerell (2006). This set included 24 isolates (21 with the 15-ADON chemotype and 3 with unusual ability to produce both DON and NIV) 
Table 1 Fusarium graminearum species complex isolates for EF-1 $\alpha$ RED Tril01 sequenced as part of this study

\begin{tabular}{|c|c|c|c|c|c|}
\hline \multirow[t]{2}{*}{ Name collection } & \multirow[t]{2}{*}{ Source/State/Country } & \multirow[t]{2}{*}{ Identification } & \multicolumn{3}{|c|}{ GenBank accession number } \\
\hline & & & $E F-1 \alpha$ gene & $R E D$ gene & Tril01 gene \\
\hline B2299 & Seed/Paraná/Brazil & F. meridionale & KT179785 & KT188371 & KT188404 \\
\hline B2301 & Seed/Paraná/Brazil & F. graminearum & KT179786 & KT188372 & KT188405 \\
\hline B2302 & Seed/Paraná/Brazil & F. graminearum & KT179787 & KT188373 & KT188406 \\
\hline $\mathrm{B} 2300$ & Seed/Paraná/Brazil & F. meridionale & KT179788 & KT188374 & KT188407 \\
\hline B2304 & Seed/Paraná/Brazil & F. meridionale & KT179789 & KT188375 & KT188408 \\
\hline B2305 & Seed/Paraná/Brazil & F. graminearum & KT179790 & KT188376 & KT188409 \\
\hline B2306 & Seed/Paraná/Brazil & F. meridionale & KT179791 & KT188377 & KT188410 \\
\hline B2307 & Seed/Paraná/Brazil & F. meridionale & KT179792 & KT188378 & KT188411 \\
\hline F5001 & Pod/Córdoba/Argentina & F. graminearum & KT179793 & KT188379 & KT188412 \\
\hline F5024 & Pod/Córdoba/Argentina & F. graminearum & KT179794 & KT188380 & KT188413 \\
\hline F5028 & Pod/Córdoba/Argentina & F. graminearum & KT179795 & KT188381 & KT188414 \\
\hline F5030 & Flower/Córdoba/Argentina & F. meridionale & JQ740897 & KT188382 & KT188415 \\
\hline F5031 & Pod/Córdoba/Argentina & F. graminearum & KT179796 & KT188383 & KT188416 \\
\hline F5036 & Seed/Córdoba/Argentina & F. cortaderiae & JQ740894 & KT188384 & KT188417 \\
\hline F5038 & Pod/Córdoba/Argentina & F. graminearum & KT179797 & KT188385 & KT188418 \\
\hline F5043 & Seed/Córdoba/Argentina & F. meridionale & JQ740895 & KT188386 & KT188419 \\
\hline F5048 & Pod/Córdoba/Argentina & F. meridionale & JQ740896 & KT188387 & KT188420 \\
\hline F5049 & Pod/Córdoba/Argentina & F. graminearum & KT179798 & KT188388 & KT188421 \\
\hline F5050 & Pod/Córdoba/Argentina & F. graminearum & JQ740892 & KT188389 & KT188422 \\
\hline F5051 & Flower/Córdoba/Argentina & F. graminearum & JQ740893 & KT188390 & KT188423 \\
\hline F5053 & Seed/Córdoba/Argentina & F. graminearum & KT179799 & KT188391 & KT188424 \\
\hline F5054 & Pod/Córdoba/Argentina & F. graminearum & KT179800 & KT188392 & KT188425 \\
\hline F5057 & Pod/Córdoba/Argentina & F. graminearum & KT179801 & KT188393 & KT188426 \\
\hline F5059 & Pod/Córdoba/Argentina & F. graminearum & KT179802 & KT188394 & KT188427 \\
\hline F5184 & Pod/Córdoba/Argentina & F. graminearum & KT179803 & KT188395 & KT188428 \\
\hline F5185 & Seed/Córdoba/Argentina & F. graminearum & KT179804 & KT188396 & KT188429 \\
\hline F5187 & Seed/Córdoba/Argentina & F. boothii & KT179805 & KT188397 & KT188430 \\
\hline F5221 & Seed/Córdoba/Argentina & F. graminearum & KT179806 & KT188398 & KT188431 \\
\hline F5222 & Pod/Córdoba/Argentina & F. graminearum & KT179807 & KT188399 & KT188432 \\
\hline F5223 & Pod/Córdoba/Argentina & F. graminearum & KT179808 & KT188400 & KT188433 \\
\hline F5225 & Pod/Córdoba/Argentina & F. graminearum & KT179809 & KT188401 & KT188434 \\
\hline F5227 & Pod/Córdoba/Argentina & F. graminearum & KT179810 & KT188402 & KT188435 \\
\hline F5228 & Seed/Córdoba/Argentina & F. graminearum & KT179811 & KT188403 & KT188436 \\
\hline
\end{tabular}

obtained from soybean plants collected in two fields in the Province of Córdoba, Argentina (Barros et al. 2012). The remaining 8 strains were isolated from soybean seeds in the Province of Parana, Brazil (5 isolates with the NIV chemotype and 3 with the $15-\mathrm{ADON}$ chemotype). The isolates were grown in complete medium (CM) for DNA extraction. DNA was extracted by means of the cetyltrimethylammnonium bromide (CTAB) method (Leslie and Summerell 2006).

Amplification of the partial translation elongation factor (EF-1, 725 bp), 3-O-acetyltransferase (Tri101, 1329 bp), and putative reductase $(R E D, 993 \mathrm{bp})$ genes sequences was performed using the E1/E2, AT1/AT2 and RED1d/RED2 primers, respectively (O'Donnell et al. 2004, 2008). PCR were carried out in a 1060 PTC-200 thermal cycler (MJ Research Inc., Watertown, MA, USA). The amplified products were purified using a Wizard ${ }^{\circledR}$ SV Gel and a PCR Clean-Up System kit (Promega, WI, USA), according to the manufacturer's instructions. Sequences were analyzed by the Sanger sequencing method using an ABI PRISM 3730 Genetic Analyzer (Applied Biosystems).

For Maximum Parsimony, the sequences from the 32 strains isolated from soybean were analysed together with the sequences from most of the species included in the FGSC to assess the evolutionary relationships. Fusarium pseudograminearum was selected as the outgroup based on results from previous studies (Starkey et al. 2007; O’Donnell 
et al. 2008). Editing of the sequences was carried out manually by using the BioEdit Sequence Alignment Editor 1997-2011. The ambiguously aligned regions in each alignment were removed by using Gblocks $V 0.91 \mathrm{~b}$. The test of substitution saturation was performed by working on the third and the first-second codon position and by using the Data Analysis in Molecular Biology and Evolution (DAMBE) $V$ 5.3.64. Three single-gene and concatenated trees were constructed by using Maximum Parsimony analyses. The different trees were compared by visual inspection and a clade was considered as an independent "phylogenetic taxon" when its basal node was well supported (bootstrap higher than $70 \%$ ) in the concatenated trees, and was not contradicted by any single-gene tree. The Maximum Parsimony (MP) analyses were conducted with the TNT program $V 1.1$, using tree-bisection-reconnection (TBR) branch-swapping algorithms and 10,000 random sequence additions per replicate, and saving 100 trees per replicate. The consistency index (CI), as well as the retention index (RI), was calculated using scrip stats.run to obtain the amount of homoplasy in the dataset.

The Maximum Parsimony results showed that the alignment of the EF-1 $\alpha$, Tri101 and RED genes sequences contained 222, 148 and 257 parsimony informative characters, respectively. The tree obtained from the analysis of Tri101 sequences supported the highest number of clades $(n=4)$ compared to the sequences trees from $E F-1 \alpha$ and RED ( $n=3$ and $n=2$, respectively). The combined dataset EF-1 $\alpha$ - Tri101 $R E D$ consisted of 2431 aligned nucleotide positions, of which 527 were parsimony informative. The parsimony analysis of these informative characters resulted in 5260 most parsimonious trees of 131 steps. The CI and the RI of the generated trees were 0.70 and 0.89 , respectively. Four lineages were identified within the FGSC once the phylogenetic tree was obtained (Fig. 1). Cluster I included the largest number $(n=23)$ of tested strains, which were DON-15ADON producers and grouped with the $F$. graminearum sensu stricto NRRL 38383 reference
Fig. 1 Consensus tree of the Fusarium graminearum species complex inferred by Maximum Parsimony from a combined data set of 3-O-acetyltransferase (Tri101), reductase (RED) and translation elongation factor $1 \alpha(E F-1 \alpha)$ genes. Numbers within the tree represent the bootstrap values, with values lower than $70 \%$ not shown

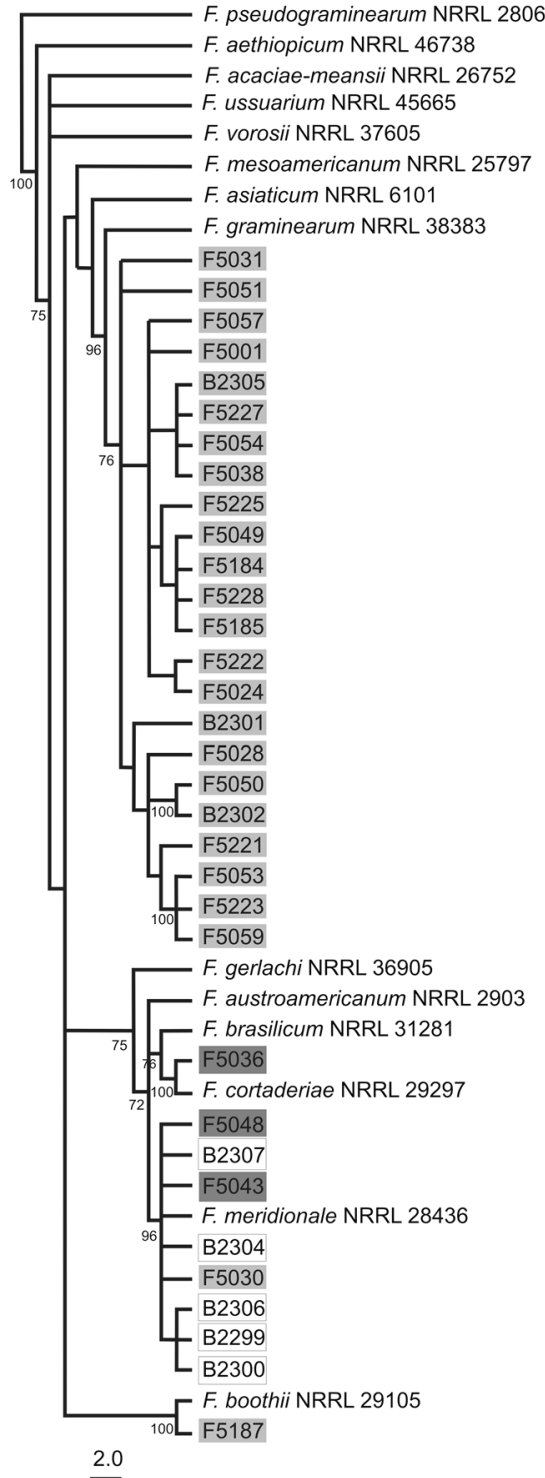

\section{F. graminearum cluster I}

| F. cortaderiae cluster ||

F. meridionale cluster III

F. boothii cluster IV 
strain (bootstrap of $96 \%$ ). Cluster II included only one DON/ NIV producing strain, which clustered with the $F$. cortaderiae NRRL 29297 reference strain (bootstrap of $100 \%$ \%). Cluster III was represented by 8 strains grouped with the $F$. meridionale NRRL 28436 reference strain (bootstrap of $96 \%$ ). All of the strains isolated from Brazil were producers of NIV, while all of the Argentinean strains were producers of DON/NIV. Cluster IV included only one DON-15ADON producing strain, which clustered together with the $F$. boothii NRRL 29105 reference strain (bootstrap of $100 \%$ ).

Although the present study has focused on a limited number of strains, this is the first report that provides evidence of the presence of at least four species within the FGSC associated with soybean in Argentina. This group of strains was previously analysed using $\mathrm{AFLP}_{\mathrm{s}}$ markers (Barros et al. 2012) and only two phylogenetic species, $F$. graminearum and F. meridionale, were detected. This study allowed resolving the identities of two new species within the FGSC, F. cortaderiae (F5036) and F. boothii (F5187), all of which was strongly supported by the MP bootstrap values.

The species composition of the FGSC appears to be host and location dependent. In Argentina, F. graminearum sensu stricto was the only phylogenetic species isolated from wheat in different subregions of the main wheat production area (Ramirez et al. 2007; Alvarez et al. 2011), but F. meridionale and F. boothii were the most important on maize in the Northwest area of Argentina (Sampietro et al. 2011). In Brazil, surveys of FGSC isolates from wheat showed that $F$. graminearum sensu stricto was the dominant species (Astolfi et al. 2012), while F. meridionale represented an $80 \%$ of the isolates from maize kernels in the Central and Southern maize growing regions of Brazil (Tessmann et al. 2011). In soybean, a preliminary report showed the presence of three species, $F$. austroamericanum, $F$. meridionale and F. cortaderiae in soybean samples from Brazil (Martinelli et al. 2004). Additionally, the present study detected $F$. graminearum sensu stricto among the Brazilian soybean strains. Based on the limited surveys to date in South America and on the results obtained in this work, we could infer that the diversity of species in the FGSC from soybean is higher than those previously reported for wheat and maize from Argentina and Brazil.

In summary, the phylogeny of the FGSC carried out in the present study allowed the identification of previously unidentified species in soybean from Argentina and Brazil. The most likely reasons could be: a) few studies conducted on this crop, b) the incomplete recognition of characterized species by conventional phenotypic identification, C) the use of unsuitable molecular tools. Thus, it would be essential to continue working on systematic molecular studies to characterize the FGSC populations from soybean isolated from Argentina and Brazil and to determine the role of soybean as a reservoir of several species within the FGSC.
Acknowledgments This work was supported by grants from Secretaría de Ciencia y Técnica, Universidad Nacional de Río Cuarto (SECyTUNRC 2012-2014) and Agencia Nacional de Promoción Científica y Tecnológica (PICT 2457/11).

\section{References}

Alvarez CL, Somma S, Proctor RH, Stea G, Mulè G, Logrieco AF, Fernandez Pinto V, Moretti A (2011) Genetic diversity in Fusarium graminearum from a major wheat-producing region of Argentina. Toxins 3:1294-1309

Astolfi P, Reynoso MM, Ramirez ML, Chulze SN, Alves TCA, Tessmann DJ, Del Ponte EM (2012) Genetic population structure and trichothecene genotypes of Fusarium graminearum isolated from wheat in southern Brazil. Plant Pathol 61:289-295

Barros GG, Alaniz Zanon MS, Abod A, Oviedo MS, Ramirez ML, Reynoso MM, Torres A, Chulze SN (2012) Natural deoxynivalenol occurrence and genotype and chemotype determination of a field population of the Fusarium graminearum complex associated with soybean in Argentina. Food Add Contam 29:293-303

Barros GG, Alaniz Zanon MS, Chiotta ML, Reynoso MM, Scandiani MM, Chulze SN (2014) Pathogenicity of phylogenetic species in the Fusarium graminearum complex on soybean seedlings in Argentina. Eur J Plant Pathol 138:215-222

Goswami RS, Kistler HC (2004) Heading for disaster: Fusarium graminearum on cereal crops. Mol Plant Pathol 5:515-525

Leslie JF, Summerell BA (2006) The Fusarium laboratory manual. Blackwell, Ames, USA

Martinelli JA, Bocchese CAC, Xie W, O’Donnell K, Kistler HC (2004) Soybean pod blight and root rot caused by lineages of Fusarium graminearum and the production of mycotoxins. Fitopatol Bras 29:492-498

O’Donnell K, Ward TJ, Geiser DM, Kistler H, Aoki T (2004) Genealogical concordance between the mating type locus and seven other nuclear genes supports formal recognition of nine phylogenetically distinct species within the Fusarium graminearum clade. Fungal Genet Biol 41:600-623

O’Donnell K, Ward TJ, Aberra D, Kistler HC, Aoki T, Orwig N, Kimura M, Bjørnstad Å, Klemsdal SS (2008) Multilocus genotyping and molecular phylogenetics resolve a novel head blight pathogen within the Fusarium graminearum species complex from Ethiopia. Fungal Genet Biol 45:1514-1522

Pioli RN, Mozzoni L, Morandi EN (2004) First report of pathogenic association between Fusarium graminearum and soybean. Plant Dis 88:220

Ramirez ML, Reynoso MM, Farnochi MC, Torres AM, Leslie JF, Chulze SN (2007) Population genetic structure of Gibberella zeae isolated from wheat in Argentina. Food Add Contam 24:1115-1120

Sampietro DA, Díaz CG, Gonzalez V, Vattuone MA, Ploper LD, Catalán CAN, Ward TJ (2011) Species diversity and toxigenic potential of Fusarium graminearum complex isolates from maize fields in northwest Argentina. Int J Food Microbiol 145:359-364

Sarver B, Ward T, Gale L, Broz K, Kistler HC, Aoki T, Nicholson P, Carter J, O'Donnell K (2011) Novel Fusarium head blight pathogens from Nepal and Louisiana revealed by multilocus genealogical concordance. Fungal Genet Biol 48:1096-1107

Starkey DE, Ward TJ, Aoki T, Gale LR, Kistler HC, Geiser DM, Suga H, Tóth B, Varga J, O’Donnell K (2007) Global molecular surveillance reveals novel Fusarium head blight species and trichothecene toxin diversity. Fungal Genet Biol 44:1191-1204

Tessmann DJ, Silva CN, Gomes LB, Faria CB, Melo MP, BarbosaTessmann IP, Lima CS, Del Ponte EM (2011) Molecular survey of toxigenic Fusarium species affecting maize kernels. In: Book of 
abstracts of the Mycored Argentina ISM 2011 conference: strategies to reduce the impact of mycotoxins in Latin America in a global context, Eds. ML Ramirez, GG Barros, S Chulze, 198, UNRC, Río Cuarto, Córdoba, Argentina.

Ward TJ, Bielawski JP, Kistler HC, Sullivan E, O’Donnell K (2002) Ancestral polymorphism and adaptive evolution in the trichothecene mycotoxin gene cluster of phytopathogenic Fusarium. Proc Natl Acad Sci U S A 99:9278-9283

Yli-Mattila T, Gagkaeva T, Ward TJ, Aoki T, Kistler HC, O’Donnell K (2009) A novel Asian clade within the Fusarium graminearum species complex includes a newly discovered cereal head blight pathogen from the Russian far east. Mycologia 101:841-852 